\title{
Protocolos de germinação e tetrazólio para a avaliação da qualidade fisiológica de sementes de Aspidosperma pyrifolium Mart.
}

\author{
Protocols to germination and tetrazolium for physiological quality evaluation of Aspidosperma \\ pyrifolium Mart.
}

Protocolos de hermanamiento y tetrazolio para la evaluación de la calidad fisiológica de semillas de Aspidosperma pyrifolium Mart.

\section{Resumo}

Protocolos de testes de germinação e tetrazólio padronizados são importantes para a análise de sementes, inclusive para a espécie Aspidosperma pyrifolium, esseencia florestal de valor econômico e ainda pouco estudada segundo a literatura, sendo, portanto, este o objetivo do presente trabalho. Assim, foram testados protocolos de Germinação (efeito de substratos e temperaturas) e Tetrazólio (efeitos de tempos de embebição e de imersão em concentrações da solução de tetrazólio). Para o teste de Germinação, os substratos rolo de papel e vermiculita e as temperaturas de 25 , 30 e $25-30^{\circ} \mathrm{C}$ apresentaram os melhores valores (médias entre $65-90 \%$ de germinação). No teste de tetrazólio o tratamento com $10 \mathrm{~h}$ de embebição e $3 \mathrm{~h}$ de imersão na solução com concentração de $0,075 \%$ (média de $90 \%$ de viabilidade) foi o melhor. Foi constatada correlação positiva (Pearson) entre a utilização do substrato papel a $25^{\circ} \mathrm{C}$ e o referido tratamento de Tetrazólio. Ambos protocolos descritos [Germinação (substrato papel a $25^{\circ} \mathrm{C}$ por oito dias) e Tetrazolio (10h de embebição e 3 h de imersão na solução com concentração de 0,075\%)] podem testados em sementes de outras populações desta espécie para a verificação da efetividade deste teste.

Palavras-chave: Caatinga; Sementes florestais; Vigor; Pereiro.

\begin{abstract}
Standardized germination and tetrazolium test protocols are important for the analysis of seeds of Aspidosperma pyrifolium, a forest species of economic value and still poorly studied according to the literature, which is the objective of the present work. Thus, the following were tested: Germination (effect of substrates and temperatures) and Tetrazolium (effects of soaking and immersion times in concentrations of the tetrazolium solution). For the germination test, the paper roll and vermiculite substrates and temperatures of 25,30 and $25-30^{\circ} \mathrm{C}$ showed the best values (means between $65-90 \%$ germination). In the tetrazolium test, the treatment with 10 hours of soaking and 3 hours of immersion in the solution with a concentration of $0.075 \%$ (average of $90 \%$ viability) was the best. A positive correlation (Pearson) was found between the use of paper substrate at $25^{\circ} \mathrm{C}$ and the abovementioned Tetrazolium treatment. Both described protocols [Germination (paper substrate at $25^{\circ} \mathrm{C}$ for eight days) and Tetrazolium (10h of imbibition and $3 \mathrm{~h}$ of immersion in the solution with a concentration of $0.075 \%)$ ] can be tested in seeds of other populations of this species for their effectiveness.
\end{abstract}

Keywords: Caatinga; Forest seeds; Vigor; Pereiro. 


\begin{abstract}
Resumen
Los protocolos estandarizados de germinación y ensayo de tetrazolio son importantes para el análisis de semillas de Aspidosperma pyrifolium, una especie forestal de valor económico y aún poco estudiada según la literatura, que es el objetivo del presente trabajo. Así, se ensayaron los siguientes: Germinación (efecto de sustratos y temperaturas) y Tetrazolio (efectos de los tiempos de remojo e inmersión en concentraciones de la solución de tetrazolio). Para la prueba de germinación, los sustratos de rollo de papel y vermiculita y temperaturas de 25,30 y $25-30^{\circ} \mathrm{C}$ mostraron los mejores valores (medias entre 65-90\% de germinación). En la prueba de tetrazolio, el tratamiento con 10 h de remojo y 3 h de inmersión en la solución con una concentración de $0.075 \%$ (promedio de $90 \%$ de viabilidad) fue el mejor. Se encontró una correlación positiva (Pearson) entre el uso de sustrato de papel a $25^{\circ} \mathrm{C}$ y el tratamiento con tetrazolio antes mencionado. Ambos protocolos descritos [Germinación (sustrato de papel a $25^{\circ} \mathrm{C}$ durante ocho días) y Tetrazolio (10h de imbibición y 3h de inmersión en la solución con una concentración de 0,075\%)] pueden ensayarse en semillas de otras poblaciones de esta especie para su eficacia.
\end{abstract}

Palabras clave: Caatinga; Sementes florestais; Vigor; Pereiro.

\title{
1. Introdução
}

Para a averiguação da qualidade fisiológica e morfológica de sementes florestais podem ser realizados os testes descritos na Regra de Análise de Sementes (RAS) (Brasil, 2009), com destaque aos testes de germinação e de tetrazólio. O teste de germinação consiste na colocação de sementes em condições ótimas de temperatura, umidade, substrato, luminosidade e período de tempo variáveis, para promover a germinação e a compreensão da fisiologia, morfologia e sanidade, assim como aferir processos que causam traumas nas sementes, e suas prováveis causas, durante a condução do mesmo. Nesse tipo de avaliação podem ser determinadas variáveis como germinação, qualidade de plântulas e sementes, assim como fatores inerentes à velocidade da germinação (Brasil, 2009).

O Teste do Tetrazólio, por sua vez, é um teste rápido em que pode ser visualizada a coloração de tecidos vegetais vivos nas sementes, em decorrência da reação de redução do sal de Tetrazólio, pela atividade de enzimas desidrogenases envolvidas na atividade respiratória. Após a reação, podem ser distinguidos tecidos com maior ou menor respiração e, a partir daí, pode ser avaliada a viabilidade da semente e a sua capacidade de produzir uma plântula normal (Fogaça, 2006).

Protocolos de avaliação de sementes florestais de algumas espécies encontradas no bioma Caatinga ainda são escassos. As espécies vegetais que compõem este bioma sofreram adaptações morfológicas e fisiológicas em resposta às condições de temperaturas elevadas e deficiência hídrica da região, portanto, a análise de suas sementes pode apresentar algumas peculiaridades. Aspidosperma pyrifolium Mart. (Apocynaceae) é um exemplo destas. Tal espécie apresenta larga ocorrência neste ambiente, sendo xerófila, heliófila e explorada como madeireira e medicamentosa (Lorenzi, 2002). Sementes de A. pyrifolium são o principal propágulo de disseminação da espécie, apresentando as seguintes características: aladas, planas, papiráceas e apresentam perda de viabilidade rapidamente após dispersão e também após armazenamento, o que exige estratégias in situ para conservação da espécie (Lima et al., 2008).

Protocolos de testes de germinação e de tetrazólio para a verificação da qualidade fisiológica de sementes de A. pyrifolium se fazem necessários para fomentar técnicas de análise e de produção comercial desta espécie, pois estes ainda são escassos (Santos et al., 2013). Desta forma, este trabalho teve como objetivo testar protocolos de testes de germinação e vig or além do teste de tetrazólio e compará-los, e contribuir para a padronização dos mesmos para avaliação da viabilidade de sementes de A. pyrifolium.

\section{Metodologia}

Coleta e beneficiamento de sementes - Frutos de Aspidosperma pyrifolium foram coletados de cerca de 30 árvores, distantes 50 metros entre si, localizadas na zona rural do município de São José do Bonfim-PB (76'28.11"S e 37¹7'54.83" W), em áreas naturais de Caatinga, no período de outubro/dezembro de 2014. Os frutos estavam em início da deiscência, e foram 
colocados em sol pleno para completar o processo, para extração e beneficiamento manual das sementes, no Laboratório de Sementes da Universidade Federal de Campina Grande (Patos, PB).

Testes de germinação e vigor - Foram testados o efeito de substratos (F1 - areia, vermiculita e rolo de papel) e temperaturas (F2 - 25, 30, e $35^{\circ} \mathrm{C}$ constantes e $25-30{ }^{\circ} \mathrm{C}$ alternada) em um esquema fatorial $3 \times 4$, perfazendo 12 tratamentos, conforme descrito na Tabela 1. Os substratos areia e vermiculita foram esterilizados em autoclave $\left(120^{\circ} \mathrm{C}\right.$ por 20 min $)$ e o papel germitest foi em estufa a $90^{\circ} \mathrm{C}$ por $24 \mathrm{~h}$.

Para a semeadura, a areia e a vermiculita foram acondicionadas em caixas gerbox e o papel germitest em forma de rolo, conforme a RAS (Brasil, 2009), e posteriormente acomodados em as câmaras de germinação nas condições descritas na Tabela 1, com o fotoperíodo de $12 \mathrm{~h}$. Cada tratamento conteve quatro repetições de 25 sementes.

Tabela 1 - Tratamentos testados na condução do teste padrão de germinação de sementes pelas variações de temperaturas e substratos em sementes de A. pyrifolium.

\begin{tabular}{cll}
\hline Substratos & Temperaturas $\left({ }^{\mathbf{0}} \mathbf{C}\right)$ \\
\hline Areia & 25 \\
& $25-30$ \\
& 30 \\
& 35 \\
\hline Vermiculita & 25 \\
& $25-30$ \\
& 30 \\
& 35 \\
\hline Rolo de papel germitest & 25 \\
& $25-30$ \\
& 30 \\
\hline
\end{tabular}

Fonte: Autores.

Durante o experimento foi avaliada a germinação, após a exposição dos cotilédones, a cada dois dias. Ao final do experimento foram avaliados: porcentagem de germinação, de sementes mortas e plântulas anormais e IVG (Brasil, 2009). O delineamento estatístico empregado foi o inteiramente casualizado, e as médias dos tratamentos testadas pelo teste de Tukey $(\mathrm{p}<0,05)$, realizados no software estatístico Sisvar®.

Teste do Tetrazólio - Na verificação da viabilidade das sementes através do teste do tetrazólio, os tratamentos consistiram nas combinações entre tempos de embebição ou pré-condicionamento (8 e 10h), tempos de imersão na solução (3 e 6h) e as concentrações da solução de Trifenil cloreto de Tetrazólio (0,075, 0,50 e 1,00\%), totalizando doze tratamentos (Tabela 2). Foram utilizadas quatro repetições com 25 sementes para cada tratamento. 
Tabela 2 - Tempos de embebição e de imersão e concentração do Tetrazólio, testadas na condução do teste de tetrazólio em sementes de A. pyrifolium.

\begin{tabular}{lll}
\hline Tempos de Embebição $(\mathbf{h})$ & Tempos de Imersão $(\mathbf{h})$ & $\begin{array}{l}\text { Concentração do } \\
\text { Tetrazólio }(\%)\end{array}$ \\
\hline 8 & 3 & 0,075 \\
8 & 3 & 0,5 \\
8 & 3 & 1 \\
8 & 6 & 0,075 \\
8 & 6 & 0,5 \\
8 & 6 & 1 \\
10 & 3 & 0,075 \\
10 & 3 & 0,5 \\
10 & 3 & 1 \\
10 & 6 & 0,075 \\
10 & 6 & 0,5 \\
10 & 6 & 1 \\
\hline
\end{tabular}

Fonte: Autores.

A embebição se deu em água destilada, nos tempos predeterminados (Tabela 2) em câmara de germinação a $30^{\circ} \mathrm{C}$ em caixas gerbox. Após os tempos de embebição, foi efetuada a remoção manual dos tegumentos das sementes, e imersão das mesmas em $200 \mathrm{ml}$ de solução de Trifenil Cloreto de Tetrazólio, cobrindo-as por completo, e mantidas nas mesmas condições da embebição, pelos tempos determinados (Tabela 2), e no escuro. Posteriormente foram lavadas e mantidas submersas em água destilada, em ambiente refrigerado até o momento da avaliação. Para avaliação das sementes foi realizado corte longitudinal no eixo embrionário, para observação da coloração dos tecidos internos, além dos cotilédones (Brasil ,2009).

A viabilidade das sementes foi avaliada através da seleção das sementes em duas categorias: sementes viáveis (viáveis e vigorosas + viáveis e não vigorosas) e não viáveis (Brasil 2009). As categorias foram adaptadas e distribuídas em oito classes pelos padrões de coloração apresentados do cotilédone e eixo embrionário, segundo Grabe (1976), International Seed Testing Association (1993) e Moore (1972), com adaptações para este estudo (Tabela 3).

Para a análise foi empregado delineamento inteiramente casualizado, no arranjo fatorial 2x2x3, que representa os tempos de embebição de imersão e as concentrações da solução, respectivamente, que totalizam 12 tratamentos com 4 repetições de 25 sementes cada. Foi aplicada a análise de variância e as médias dos tratamentos comparadas através do teste de Tukey $(\mathrm{p}<0,05)$ empregando-se o software estatístico Sisvar® para a análise.

Comparação entre os testes de germinação e tetrazólio - A análise da correlação de Pearson foi usada para correlacionar os melhores resultados dos experimentos de Tetrazólio e Germinação. Para tal ação, foram escolhidos os tratamentos que se destacaram dentre os demais, levando em consideração os resultados dos testes de médias em função de cada ensaio em separado. Para o experimento de Tetrazólio optou-se também pelo tratamento que foi realizado em menor período de tempo. 
Logo, para melhor analisar a proposição da análise de Person, levou-se em consideração como critérios de classificação de correlação, quando o coeficiente $r$ indicasse haver correlação positiva ou negativa entre as variáveis testadas, segundo a metodologia descrita por Medeiros et al. (2020). As análises foram realizadas no R.

Tabela 3 - Descrição das colorações apresentadas pelo embrião e características das sementes de acordo com as categorias e classes a serem empregadas na análise da viabilidade de sementes de A. Pyrifolium (Brasil, 2009).

\begin{tabular}{lll}
\hline CATEGORIAS & CLASSES & CARACTERIZAÇÃO \\
\hline $\begin{array}{l}\text { Viáveis e } \\
\text { vigorosas }\end{array}$ & Classe I & Embrião com coloração rosa uniforme e todos os tecidos com aspecto normal e firme \\
& Classe II & $\begin{array}{l}\text { Menos de } 50 \% \text { dos cotilédones com coloração vermelha intensa, típico de tecido em } \\
\text { deterioração }\end{array}$ \\
\hline $\begin{array}{l}\text { Viáveis não } \\
\text { vigorosas }\end{array}$ & Classe III & $\begin{array}{l}\text { Extremidade da radícula com coloração branco leitosa sem atingir o cilindro central, } \\
\text { além de apresentar manchas branco leitosas e vermelha intensa dispersas. }\end{array}$ \\
& Classe IV & $\begin{array}{l}\text { Semente apresentando menos de 50\% da região cotiledonar com coloração branco } \\
\text { leitosa, caracterizando tecido morto }\end{array}$ \\
\hline Classe V VI & $\begin{array}{l}\text { Eixo embrionário e mais de 50\% da região cotiledonar apresentando coloração } \\
\text { vermelho intensa, típica de tecidos em deterioração. }\end{array}$ & $\begin{array}{l}\text { Semente totalmente com coloração vermelha intensa, indicando processo acentuado de } \\
\text { deterioração. } \\
\text { Não viáveis }\end{array}$ \\
& Classe VII & $\begin{array}{l}\text { Eixo embrionário com coloração branco leitosa, apresentando o cilindro central com } \\
\text { coloração vermelho intensa. Região cotiledonar apresentando mais de 50\% com } \\
\text { coloração branco leitosa, podendo haver manchas vermelhas intensas dispersas. } \\
\text { Eixo embrionário com coloração vermelho } \\
\text { intenso e tecidos flácidos. }\end{array}$ \\
\hline
\end{tabular}

Fonte: Autores.

\section{Resultados e Discussão}

\section{Testes de germinação e vigor}

Por meio da avaliação dos resultados obtidos para o teste de germinação e vigor podem ser visualizadas importantes informações sobre a germinação de A. pyrifolium em laboratório. Assim, em relação a ANOVA, para o fator substrato pode ser visualizado que existem diferenças significativas para este fator, em todas as variáveis analisadas $(\mathrm{p}<0,05)$. Enquanto que para o fator temperatura, somente as variáveis Germinação e IVG apresentaram diferenças significativas entre as testadas $(\mathrm{p}<0,05)$. A interação entre os fatores testados (substratos e temperaturas) pode ser visualizada que todas as variáveis analisadas apresentaram diferenças significativas entre os tratamentos $(\mathrm{p}<0,05)$, exceto para o percentual de Plântulas Anormais (A\%) (Tabela 4). 
Tabela 4 - Anova e teste de médias (Tukey) para as variáveis percentagem de Germinação (G), Sementes Mortas (M), Plântulas Anormais (A) e Índice de Velocidade de Germinação (IVG), com F1 - Substratos e F2 - Temperaturas, para sementes e plântulas de A. pyrifolium.

\begin{tabular}{|c|c|c|c|c|c|}
\hline \multicolumn{6}{|c|}{ VARIÁVEIS } \\
\hline & & $\mathbf{G}$ & $\mathbf{M}$ & $\mathbf{A}$ & IVG \\
\hline FV & GL & \multicolumn{4}{|c|}{$\mathbf{F}$} \\
\hline Substratos (F1) & 2,00 & $148,784 * *$ & $87,429 * *$ & $12,84 * *$ & $180,192 * *$ \\
\hline Temperaturas (F2) & 3,00 & $25,781 * *$ & $2,380 \mathrm{~ns}$ & $1,571 \mathrm{~ns}$ & $39,403 * *$ \\
\hline Substratos (F1) x Temperaturas (F2) & 2 & $8,271 * *$ & $26,498 * *$ & $1,528 \mathrm{~ns}$ & $12,95 * *$ \\
\hline CV $(\%)$ & & 25,28 & 35,01 & 83,24 & 22,89 \\
\hline Média Geral & & 48,83 & 37,50 & 7,41 & 0,92 \\
\hline FATORES & \multicolumn{5}{|c|}{ TESTE DE MÉDIAS* } \\
\hline \multirow{6}{*}{ Substratos (F1) } & Areia & $7,00 \mathrm{a}$ & $72,00 \mathrm{c}$ & $2,25 \mathrm{a}$ & $0,124 \mathrm{a}$ \\
\hline & Vermiculita & $59,50 \mathrm{~b}$ & $27,25 \mathrm{~b}$ & $13,25 \mathrm{~b}$ & $1,16 \mathrm{~b}$ \\
\hline & Rolo de Papel & $80,00 \mathrm{c}$ & $13,25 \mathrm{a}$ & $6,75 \mathrm{a}$ & $1,47 \mathrm{c}$ \\
\hline & Erro Padrão & 3,09 & 3,28 & 1,54 & 0,05 \\
\hline & 25 & $57,33 \mathrm{~b}$ & $38,33 \mathrm{a}$ & $4,33 \mathrm{a}$ & $1,13 \mathrm{~b}$ \\
\hline & $25-30$ & $61,33 \mathrm{~b}$ & $31,00 \mathrm{a}$ & $7,66 \mathrm{a}$ & $1,17 \mathrm{~b}$ \\
\hline \multirow[t]{3}{*}{ Temperaturas (F2) $-{ }^{\circ} \mathrm{C}$} & 30 & $54,66 \mathrm{~b}$ & 35,66 a & $8,00 \mathrm{a}$ & $1,02 \mathrm{~b}$ \\
\hline & 35 & $22,00 \mathrm{a}$ & $45,00 \mathrm{a}$ & $9,66 \mathrm{a}$ & $0,35 \mathrm{a}$ \\
\hline & Erro Padrão & 3,56 & 3,78 & 1,78 & 0,06 \\
\hline
\end{tabular}

*Letras diferentes nas colunas indicam diferenças estatísticas entre os valores médios. Fonte: Autores.

Em virtude dos fatores em separado, pode ser descrito que para as variáveis G e IVG o substrato rolo de papel foi diferente dos demais (maiores valores) e a temperatura de $35^{\circ} \mathrm{C}$ (menores valores) foi diferente das demais e ainda inferior a estas. Para a variável M, o rolo de papel (menor valor) foi diferente estatisticamente da vermiculita e da areia e não houve diferenças estatísticas entre as temperaturas. Para a variável A\%, o rolo de papel (menor valor) igual a areia é diferente estatisticamente da vermiculita e ainda não houve diferenças estatísticas entre as temperaturas (Tabela 4).

O desempenho das sementes foi superior no substrato rolo de papel com maior germinação, e IVG e menor porcentagem de mortalidade, enquanto a temperatura de $35^{\circ} \mathrm{C}$ promoveu maior porcentagem de Sementes Mortas e menor IVG. A análise da interação entre os fatores testados nesta pesquisa, mostrou que o percentual de Germinação (G\%) e o índice de Velocidade de Germinação (IVE) nos substratos vermiculita e rolo de papel e nas temperaturas de 25 e 30 constantes e 25 $30{ }^{\circ} \mathrm{C}$ alternadas, foram condições que favoreceram a expressão da viabilidade das sementes, com diferenças estatísticas das demais condições testadas e com maiores médias. Já para a variável percentagem de Sementes Mortas (M\%) o substrato areia e a temperatura de $35^{\circ} \mathrm{C}$ promoveram maior mortalidade (Tabelas 4 e 5). 
Tabela 5 - Interação entre fatores com o Teste de médias (Tukey) para as variáveis percentagem de Germinação (G), Sementes Mortas (M), Índice de Velocidade de Germinação (IVG), com F1 - Substratos e F2 - Temperaturas, para sementes de A. pyrifolium.

\section{MÉDIAS (F1 x F2)*}

\section{Substratos (F1)}

Areia Vermiculita Rolo de Papel

\section{GERMINAÇÃO $(\%)$}

$\begin{array}{ccccc} & 25 & 3,00 \mathrm{Aa} & 86,00 \mathrm{Bb} & 82,00 \mathrm{Bb} \\ \text { Temperaturas (F2) - }{ }^{\circ} \mathbf{C} & 25-30 & 18,00 \mathrm{Aa} & 80,00 \mathrm{Bb} & 86,00 \mathrm{Bab} \\ & 30 & 7,00 \mathrm{Aa} & 65,00 \mathrm{Bb} & 92,00 \mathrm{Cb} \\ & 35 & 0,00 \mathrm{Aa} & 6,00 \mathrm{Aa} & 60,00 \mathrm{Aa}\end{array}$

Erro Padrão

6,17

\section{SEMENTES MORTAS (\%)}

$\begin{array}{ccccc} & 25 & 97,00 \mathrm{Bb} & 5,00 \mathrm{Aa} & 13,00 \mathrm{Ab} \\ \text { Temperaturas (F2) - }{ }^{\circ} \mathbf{C} & 25-30 & 77,00 \mathrm{Bb} & 11,00 \mathrm{Aa} & 5,00 \mathrm{Aa} \\ & 30 & 89,00 \mathrm{Bb} & 15,00 \mathrm{Aa} & 3,00 \mathrm{Aa} \\ & 35 & 25,00 \mathrm{Aa} & 78,00 \mathrm{~B} \mathrm{~b} & 32,00 \mathrm{Ab} \\ \text { Erro Padrão } & & & 6,56 & \end{array}$

\section{ÍNDICE DE VELOCIDADE DE GERMINAÇÃO}

$\begin{array}{ccccc} & 25 & 0,04 \mathrm{Aa} & 1,67 \mathrm{Bb} & 1,67 \mathrm{Bb} \\ \text { Temperaturas (F2) - }{ }^{\circ} \mathbf{C} & 25-30 & 0,31 \mathrm{Aa} & 1,72 \mathrm{Bc} & 1,47 \mathrm{Bb} \\ & 30 & 0,13 \mathrm{Aa} & 1,18 \mathrm{Bb} & 1,76 \mathrm{Cb} \\ & 35 & 0,00 \mathrm{Aa} & 0,07 \mathrm{Aa} & 0,99 \mathrm{Aa}\end{array}$

Erro Padrão

0,1

*Letras maiúsculas diferentes nas colunas indicam diferenças estatísticas entre os valores médios para o F1 e letras minúsculas diferentes nas linhas indicam diferenças estatísticas entre os valores médios para o F2. Fonte: Autores.

A maior porcentagem de germinação constatada no substrato rolo de papel corroboram com os encontrados por Guedes et al. (2009) estudando a germinação de sementes de Cereus jamacaru. O rolo de papel também demonstrou ser o substrato indicado para a germinação de sementes de Cariniana estrellensis, na temperatura de $25^{\circ} \mathrm{C}$ (Kopper et al., 2010). Sementes de Cnidosculus phyllacanthus também tiveram germinação superior quando utilizados o substrato rolo de papel germitest e as temperaturas constantes de 25 e $30^{\circ} \mathrm{C}$ e alternada de 25-30 $\mathrm{C}$ (Silva \& Aguiar 2004). Em sementes de Jacaranda mimosifolia o papel germitest também apresentou melhores resultados durante a condução do teste germinativo associado à temperatura constante de $25^{\circ} \mathrm{C}$ (Maciel et al., 2013). Para Lima e Garcia (1996), o substrato papel na forma de rolo concede algumas vantagens às sementes em germinação, como o melhor desenvolvimento das estruturas essenciais das plântulas, permitindo assim, maior rapidez, facilidade e segurança na avaliação do teste, além de ocupar menor espaço no 
germinador, o que possibilita a execução de maior número de análises simultaneamente.

A análise da influência da temperatura sobre a porcentagem de germinação, de sementes mortas e plântulas anormais de A. pyrifolium apontou diferenças numéricas entre estas $(\mathrm{p}<0,05)$ (Tabela 4$)$.

As temperaturas constantes de 25 e $30^{\circ} \mathrm{C}$ e a alternada $\left(25-30^{\circ} \mathrm{C}\right)$ não diferiram estatisticamente entre si, em nenhum dos parâmetros analisados, enquanto a temperatura de $35^{\circ} \mathrm{C}$ mostrou-se inadequada para a condução do teste de germinação, pela maior mortalidade de sementes e anormalidade de plântulas (Tabelas 4 e 5).

Estudos com sementes de Luetzelburgia auriculata também pode ser constatado que houve redução na germinação com o emprego de altas temperaturas, acima de $35^{\circ} \mathrm{C}$ (Nogueira et al. 2012). A germinação de sementes de Blepharocalyx salicifolius apresentou os menores valores na temperatura de $35^{\circ} \mathrm{C}$ (Rego et al. 2009).

Mondo et al. (2008) constataram que a temperatura de $25^{\circ} \mathrm{C}$ é adequada para germinação de sementes de Parapiptadenia rigida, uma espécie encontrada na Caatinga, com o emprego do substrato vermiculita, independentemente da presença ou ausência da luminosidade. Em estudos com sementes de Dalbergia nigra foi constatado que para a germinação das sementes dessa espécie devem-se utilizar temperaturas constantes de 20 e $30^{\circ} \mathrm{C}$, além das alternadas $20-30^{\circ} \mathrm{C}$ e $20-35^{\circ} \mathrm{C}$ com substrato vermiculita (Andrade et al., 2006). Estudos com Myracrodruon urundeuva, uma espécie comum no ambiente do bioma Caatinga, apontaram que a temperatura de $35^{\circ}$ não foi adequada para a germinação das sementes, independentemente dos substratos utilizado (Pacheco et al. 2006) enquanto temperaturas acima $35^{\circ} \mathrm{C}$ não foram eficazes no processo germinativo de sementes de Luetzelburgia auriculata, uma outra espécie comum no ambiente do bioma Caatinga (Nogueira et al., 2012). Estes resultados corroboram com os aqui encontrados para a germinação de sementes de Aspidosperma pyrifolium..

Para Carvalho e Nakagawa (2000) e Varela et al. (2005) em sementes sujeitas a temperaturas mais altas (acima de $30^{\circ} \mathrm{C}$ ), a velocidade de absorção de água e as atividades enzimáticas tornam-se mais elevadas, fazendo com que as sementes germinam mais rapidamente. Entretanto, a partir de um determinado nível, podem ser prejudiciais à germinação de algumas espécies, provavelmente por causarem a desnaturação de proteínas essenciais ao processo germinativo. Para a espécie em questão foi observada redução acentuada na porcentagem de germinação na temperatura constante de $35^{\circ} \mathrm{C}$ (Tabelas 4 e 5). No entanto, a resposta das sementes aos fatores importantes e que interferem no processo germinativo como temperaturas, substratos e luminosidade, se dá de forma individualizada e diferenciada, o que justifica a importância de estudos que auxiliem a compreensão e interpretação das análises para as mais diferentes espécies (Guedes et al., 2009).

Na Tabela 4 pode ser observado que nas temperaturas de 25, 25-30 e $300 \mathrm{C}$ e nos substratos vermiculita e rolo de papel germitest, forneceram condições adequadas para a germinação das sementes. Nesse sentido, pode ser destacada a temperatura de $30^{\circ} \mathrm{C}$ e o emprego do substrato rolo de papel germitest, por conta dos seus maiores valores obtidos.

A areia demonstrou ser o pior substrato para a germinação das sementes, neste estudo, com maior mortalidade, em todas as temperaturas testadas (Tabelas 4 e 5). O substrato areia é um ótimo condutor de calor, e outra característica do mesmo é a tendência de que a água fornecida às sementes na condução do teste, ficar depositada no fundo das caixas tipo Gerbox, o que pode tornar as condições menos favoráveis para a germinação a altas temperaturas, que exigem maior disponibilidade de água às sementes, por haver maior velocidade de absorção.

Observou-se também que com o aumento da temperatura para $35^{\circ} \mathrm{C}$, os substratos rolo de papel e a vermiculita apresentaram maior mortalidade, com valores mais elevados neste último. A mortalidade foi menor nas outras temperaturas testadas, sem diferenças estatísticas significativas dentro dos substratos, à exceção do rolo de papel a $30^{\circ} \mathrm{C}$, com a menor porcentagem de mortalidade (Tabelas 4 e 5).

\section{Teste de Tetrazólio}

Os resultados obtidos em relação ao teste de tetrazólio, com referência aos três fatores testados [F1 - Embebição (E), 
F2 - Imersão (I) e F3- Concentração (C)], em sementes de A. pyrifolium, foram importantes para o entendimento de particularidades sobre esta espécie. Foram observadas diferenças significativas $(p<0,01)$ para os fatores isolados E e $C$, para as interações entre Embebição e Concentração $(p<0,01)$ e Embebição e Imersão $(p<0,05)$ para as variáveis sementes viáveis (viáveis e vigorosas + viáveis e não vigorosas) e não viáveis. O demais fatores e interações não foram significativos (Tabelas 6 e 7).

Tabela 6 - Anova e teste de médias (Tukey) para as variáveis percentagem de sementes viáveis e não viáveis em virtude do esquema fatorial 2x2x3, com F1 - Embebição (E), F2 - Imersão (I) e F3- Concentração (C), para sementes e plântulas de $A$. pyrifolium tratadas com Tetrazólio.

\section{ANOVA}

\begin{tabular}{|c|c|c|c|c|c|}
\hline & \multirow{2}{*}{ FV } & & \multirow{2}{*}{ GL } & \multicolumn{2}{|c|}{$\mathbf{F}$} \\
\hline & & & & Viáveis & Não viáveis \\
\hline \multicolumn{3}{|c|}{ E } & 1 & $57,093 * *$ & $57,093 * *$ \\
\hline \multicolumn{3}{|c|}{ I } & 1 & $1,683 \mathrm{~ns}$ & $1,683 \mathrm{~ns}$ \\
\hline \multicolumn{3}{|c|}{$\mathrm{C}$} & 2 & $20,837 * *$ & $20,837 * *$ \\
\hline \multicolumn{3}{|c|}{ E X I } & 1 & $4,247 *$ & $4,247 *$ \\
\hline \multicolumn{3}{|c|}{$\mathrm{EXC}$} & 2 & $5,819 * *$ & $5,819 *$ \\
\hline \multicolumn{3}{|c|}{ IXC } & 2 & $2,208 \mathrm{~ns}$ & $2.208 \mathrm{~ns}$ \\
\hline \multicolumn{3}{|c|}{ IX C X E } & 2 & $1,311 \mathrm{~ns}$ & $1.311 \mathrm{~ns}$ \\
\hline \multicolumn{3}{|c|}{$\mathrm{CV}(\%)$} & & 9,22 & 42.22 \\
\hline \multicolumn{3}{|c|}{ Média Geral } & & 82,08 & 17,91 \\
\hline \multicolumn{6}{|c|}{ MÉDIAS - FATORES EM SEPARADO - Percentuais * } \\
\hline \multicolumn{6}{|c|}{ E (h) } \\
\hline \multirow{3}{*}{ Variáveis } & \multirow{3}{*}{\multicolumn{2}{|c|}{$\begin{array}{c}\text { viáveis } \\
\text { Não - Viáveis }\end{array}$}} & 8 & 10 & Erro \\
\hline & & & $73,83 \mathrm{a}$ & $90,33 \mathrm{~b}$ & 1,54 \\
\hline & & & $9,66 \mathrm{a}$ & $26,16 \mathrm{~b}$ & 1,54 \\
\hline \multicolumn{6}{|c|}{$\mathbf{I}(\mathbf{h})$} \\
\hline \multirow{3}{*}{ Variáveis } & \multirow{3}{*}{\multicolumn{2}{|c|}{$\begin{array}{c}\text { viáveis } \\
\text { Não - Viáveis }\end{array}$}} & 3 & 6 & Erro \\
\hline & & & $83,50 \mathrm{a}$ & 80,66 a & 1,54 \\
\hline & & & $16,50 \mathrm{a}$ & $19,00 \mathrm{a}$ & 1,54 \\
\hline \multicolumn{6}{|c|}{$\mathrm{C}(\%)$} \\
\hline \multirow{3}{*}{ Variáveis } & \multirow{3}{*}{$\begin{array}{l}\text { não viáveis } \\
\text { Viáveis }\end{array}$} & 0,075 & 0,50 & 1,00 & Erro \\
\hline & & $89,25 \mathrm{~b}$ & $84,50 \mathrm{~b}$ & $72,50 \mathrm{a}$ & 1,54 \\
\hline & & $10,75 \mathrm{a}$ & $15,50 \mathrm{a}$ & $27,50 \mathrm{~b}$ & 1,89 \\
\hline
\end{tabular}

*Letras diferentes nas linhas indicam diferenças estatísticas entre os valores médios. Fonte: Autores. 
Tabela 7 - Valores médios para variáveis percentagem de sementes viáveis e não viáveis em virtude do esquema fatorial 2x2x3, com F1 - Embebição (E), F2 - Imersão (I) e F3- Concentração (C), para sementes de A. pyrifolium no teste de Tetrazólio.

\begin{tabular}{|c|c|c|c|c|c|c|c|}
\hline \multicolumn{8}{|c|}{ MÉDIAS - E x I - Percentuais ${ }^{1}$} \\
\hline & \multicolumn{2}{|c|}{ VARIÁVEIS } & \multicolumn{2}{|c|}{ Viáveis } & & \multicolumn{2}{|c|}{ Não - Viáveis } \\
\hline \multicolumn{3}{|c|}{ I (h) } & 3 & 6 & & 3 & 6 \\
\hline \multirow{3}{*}{$\mathbf{E}(\mathbf{h})$} & & $8 \mathrm{~h}$ & $73,00 \mathrm{Aa}$ & $74,00 \mathrm{Aa}$ & & $27,00 \mathrm{Ab}$ & $6,00 \mathrm{Aa}$ \\
\hline & & $10 \mathrm{~h}$ & $94,00 \mathrm{Bb}$ & $86,66 \mathrm{Aa}$ & & $25,33 \mathrm{Ab}$ & $13,33 \mathrm{Ba}$ \\
\hline & \multicolumn{2}{|c|}{ Erro } & \multicolumn{2}{|c|}{2,18} & & \multicolumn{2}{|c|}{2,18} \\
\hline \multicolumn{8}{|c|}{ MÉDIAS - E x C - Percentuais ${ }^{1}$} \\
\hline \multirow{2}{*}{\multicolumn{5}{|c|}{$\mathrm{C}(\%)$}} & $\mathbf{E}(\mathbf{h})$ & & Erro \\
\hline & & & & & $8 \mathrm{~h}$ & $10 \mathrm{~h}$ & \\
\hline \multicolumn{5}{|c|}{0,075} & $84,00 \mathrm{Ba}$ & $94,50 \mathrm{Ab}$ & 2,67 \\
\hline \multicolumn{5}{|c|}{ Viáveis } & $78,50 \mathrm{Ba}$ & $90,50 \mathrm{Ab}$ & \\
\hline & & & \multicolumn{2}{|l|}{1} & $59,00 \mathrm{Aa}$ & $86,00 \mathrm{Ab}$ & \\
\hline \multirow{3}{*}{\multicolumn{2}{|c|}{ ARIÁVEIS }} & & \multicolumn{2}{|l|}{0,075} & $5,50 \mathrm{a}$ & $16,00 \mathrm{~b}$ & 2,67 \\
\hline & & Não - Viáveis & \multicolumn{2}{|l|}{0,5} & $9,50 \mathrm{a}$ & $21,50 \mathrm{~b}$ & \\
\hline & & & \multicolumn{2}{|l|}{1} & $41,00 \mathrm{~b}$ & $14,00 \mathrm{a}$ & \\
\hline \multicolumn{8}{|c|}{ MÉDIAS - E x I x C - Percentuais ${ }^{2}$} \\
\hline \multicolumn{8}{|c|}{ Viáveis } \\
\hline \multirow{2}{*}{\multicolumn{2}{|c|}{$\begin{array}{c}\text { I (h) } \\
\text { Concentração (\%) }\end{array}$}} & \multicolumn{3}{|c|}{$3 \mathbf{h}$} & \multicolumn{3}{|c|}{$6 \mathrm{~h}$} \\
\hline & & 0,075 & 0,5 & 1 & $\mathbf{0 , 0 7 5}$ & 0,5 & 1 \\
\hline \multirow{2}{*}{$\mathbf{E}(\mathbf{h})$} & $8 \mathrm{~h}$ & 85,00 & 74,00 & 60,00 & 83,00 & 83,00 & 58,00 \\
\hline & $10 \mathrm{~h}$ & 95,00 & 93,00 & 94,00 & 94,00 & 88,00 & 78,00 \\
\hline \multicolumn{4}{|c|}{ Erro } & \multicolumn{4}{|c|}{3,78} \\
\hline \multicolumn{8}{|c|}{ Não viáveis } \\
\hline \multirow{2}{*}{\multicolumn{2}{|c|}{$\begin{array}{c}\text { I (h) } \\
\text { Concentração (\%) }\end{array}$}} & \multicolumn{3}{|c|}{$3 \mathrm{~h}$} & \multicolumn{3}{|c|}{$6 \mathrm{~h}$} \\
\hline & & 0,075 & 0,5 & 1 & 0,075 & 0,5 & 1 \\
\hline \multirow{2}{*}{ E (h) } & $8 \mathrm{~h}$ & 15,00 & 26,00 & 40,00 & 17,00 & 17,00 & 42,00 \\
\hline & $10 \mathrm{~h}$ & 5,00 & 7,00 & 6,00 & 6,00 & 12,00 & 22,00 \\
\hline & & Erro & & & & & \\
\hline
\end{tabular}

${ }^{1}$ Letras maiúsculas diferentes nas linhas e maiúsculas nas colunas, indicando diferenças estatísticas entre os valores médios ${ }^{2} \mathrm{~N}$ esse quesito não houve diferenças estatísticas segundo o teste F, logo os valores não foram testados com o teste de médias. Fonte: Autores.

Em relação ao fator Embebição, a condição de 10h foi mais eficiente na avaliação da qualidade fisiológica das sementes (90,33\% sementes viáveis) em todas as concentrações e tempos de imersão testados (Tabela 6). As concentrações da solução de 0,075 e $0,50 \%$, com 89,25 e 84,5\% de sementes viáveis, respectivamente, também foram mais adequadas para a condução do teste de tetrazólio, pois o aumento para $1 \%$ diminui a avaliação de sementes viáveis para $72,5 \%$. Sugere-se então o tempo de 10 horas para condução do teste do tetrazólio para a espécie, assim como a concentração da solução de $0,075 \%$, por questões de economia na quantidade de sal a ser utilizado no teste (Tabelas 6 e 7). 
Em relação às interaçães, para ExI, o maior valor obtido é diferente dos demais, foi a combinação de embebição de $10 \mathrm{~h}$ com a imersão de $3 \mathrm{~h}$ para as sementes viáveis. A avaliação da interação ExC em relação às sementes viáveis, mostrou que a embebição de 10h foi mais adequada e diferente das demais, bem como as concentrações de 0,0075 e 0,5\% (Tabelas 6 e 7).

Em relação a interação entre os três fatores, podem ser destacados que a concentração de $0,075 \%$, a imersão de $3 \mathrm{~h}$ e o embebição de $10 \mathrm{~h}$ são mais adequados para a avaliação das sementes viáveis.

A coloração alcançada pelas sementes após a exposição ao Trifenil Cloreto de Tetrazólio, em diferentes tempos de embebição e imersão é um fator importante na avaliação dos testes de tetrazólio, por interferir nas condições da análise pelo o avaliador do teste.

Neste estudo, os tratamentos que possibilitaram melhor visualização, e consequente avaliação da coloração apresentada pelas sementes foram o T8 (tempo de embebição de 10 horas e imersão por 3 horas na solução de Trifenil Cloreto de Tetrazólio na concentração de 0,5\%) e T10 (tempo de embebição de 10 horas e imersão por 6 horas na solução de Trifenil Cloreto de Tetrazólio na concentração de $0,075 \%$ ). Neste último tratamento a coloração apresenta-se nítida, o que facilitou as análises. Na concentração de $1 \%$ do sal de tetrazólio verificou-se coloração mais intensa (Figura 1), que dificultou as análises quanto à determinação das categorias e classes, concordando com os resultados de Costa e Santos (2010) nos estudos com sementes de Leucaena leucocephala, com emprego da mesma concentração da solução do Tetrazólio. Para estes autores os resultados dos testes de tetrazólio serão satisfatórios se a solução de tetrazólio for adequadamente absorvida pelas sementes e, estas, quando viáveis, absorverem a solução lentamente, desenvolvendo coloração suave, diferentemente das sementes deterioradas, as quais tendem a adquirir coloração rosa forte. A avaliação da coloração apresentada pelas sementes deve ser realizada com atenção, pois cada espécie possui suas particularidades na estrutura da semente o que pode dificultar as análises (Mendes et al., 2009).

Figura 1 - Coloração apresentada na concentração de 1\% da solução do sal de Tetrazólio em sementes de A. pyrifolium.

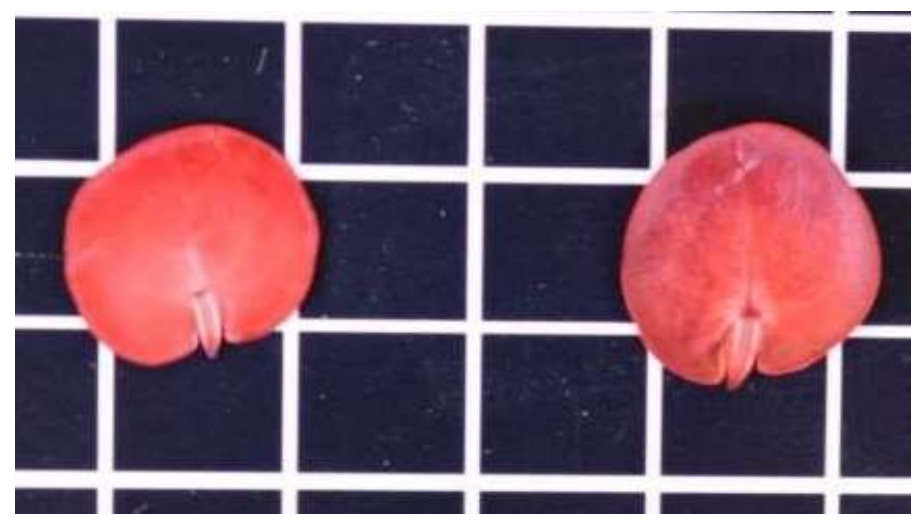

Fonte: Autores.

Para Amburana cearenses o tempo de embebição na solução foi diminuído de seis para três horas, com o aumento da temperatura de embebição das sementes de 35 para 400C, o que reduziu o tempo de realização do teste (Guedes et al., 2010). Para Fogaça et al. (2006), o tempo de imersão de 3 horas também foi o ideal para a coloração apropriada na verificação de sementes de Gleditschia amorphoides.

Em estudos com sementes de Ceiba speciosa foi observado que a concentração de 0,5\% da solução do sal de tetrazólio com tempo de imersão de quatro horas foram os tratamentos indicados para a espécie (Lazarotto et al., 2011). Esta mesma concentração de solução foi ideal para verificar a viabilidade de sementes de Ipê amarelo, mas com tempo de imersão na solução por 12 horas (Oliveira et al. 2005). 
Alguns testes podem apresentar condições adequadas para análises com baixas concentrações da solução do sal de tetrazólio e períodos longos de imersão como nos estudos com sementes de Ipê branco que testou a concentração de $0,05 \%$ e tempo de imersão de 24 horas e os indicou como adequada para avaliar a viabilidade das sementes dessa espécie (Abbade \& Massanori, 2014).

Outros testes que utilizaram concentrações maiores da solução do sal de tetrazólio encontraram condições adequadas para se avaliar a viabilidade de sementes, como na avaliação da espécie Dimorphandra wilsonii que foi utilizada concentração de $1 \%$ por 48 horas e permitiu boa avaliação da viabilidade das sementes (Freitas, 2009).

A Figura 2 apresenta a coloração encontrada nas classes de sementes que foram utilizadas na fase de avaliação da viabilidade de sementes de A. pyrifolium de acordo com os tratamentos empregados, à exceção da classe VI, pois não foram encontradas sementes com características determinadas para esta classe, ou seja, coloração vermelho intensa que indica processo acentuado de deterioração dos tecidos.

Diversas concentrações já foram testadas em espécies florestais e na condução deste teste, com variações daquela adequada para avaliação da espécie. Em estudos com Araucaria angustifolia constatou-se que tanto a concentração de $0,1 \%$ como a de $0,5 \%$ e tempo de imersão de 1 hora foram métodos eficazes na avaliação da qualidade de sementes da espécie (Oliveira et al., 2014).

Nogueira et al. (2014) encontraram a combinação ideal para sementes de Enterolobium contortisiliquum aplicando concentrações de 0,05 e 0,075\% no período de três horas de imersão. Oliveira et al. (2005) também encontraram para sementes de Ipê amarelo como metodologia eficiente o uso da concentração de $0,07 \%$ para avaliar a viabilidade de sementes dessa espécie.

Resultados divergentes dos encontrados por (Cunha \& Gomes, 2015) pesquisando sementes de Mulungu, na qual não encontraram diferenças significativas entre tempos de imersão e embebição na condução do teste de tetrazólio para a espécie. Brenha et al. (2012) concluiu que para sementes de Pinhão bravo, o teste de tetrazólio deve ser procedido na concentração de 0,5\% com tempo de imersão de 6 horas. Para Garlet et al. (2015) o tratamento que possibilitou melhores condições de análises de sementes de Cassia leptophylla foi na utilização da solução com concentração de 1,5\% por duas horas e pré-condicionadas por vinte e quatro horas.

Figura 2 - Caracterização das classes de viabilidade apresentadas no teste do tetrazólio em sementes de A. pyrifolium.
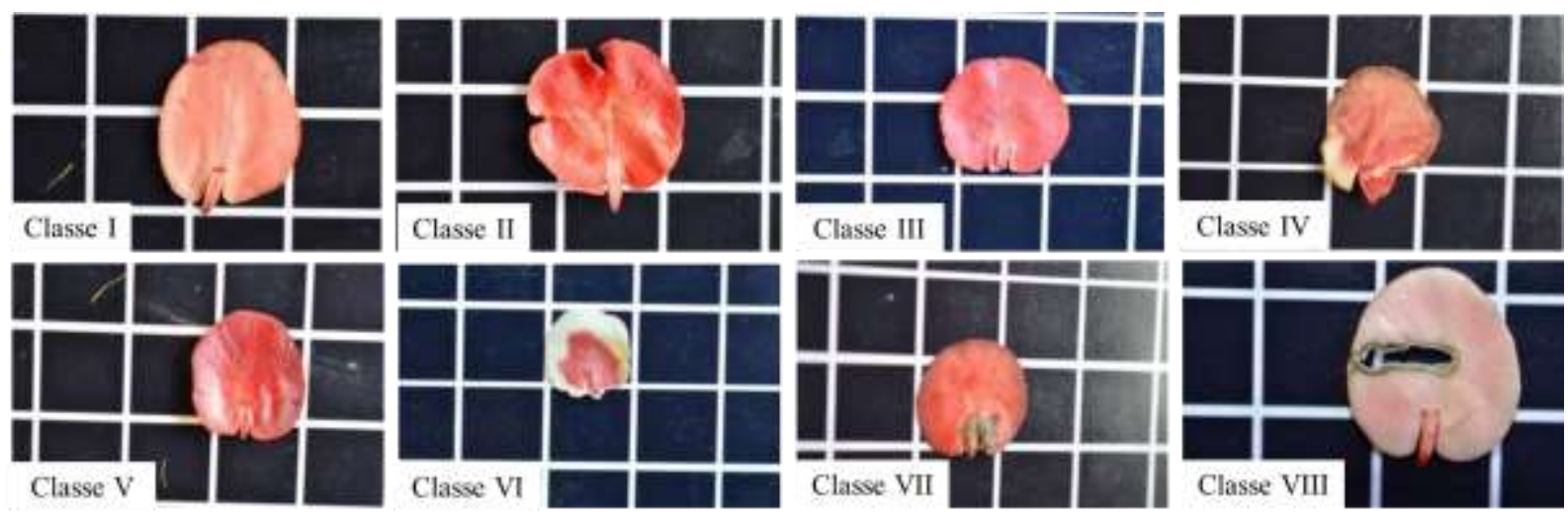

Legenda: Todos os quadrados descritos na cor branca têm a medida de $1 \mathrm{~cm}^{2}$. Fonte: Autores.

\section{Comparação entre os testes de Germinação e tetrazólio}

Em virtude da análise da Correlação de Pearson foram utilizados, no experimento de germinação, os tratamentos dos 
substratos Vermiculita e Rolo de Papel nas temperaturas constantes de 25,30 e $25-30^{\circ} \mathrm{C}$ alternada (em separado) e, no experimento de Tetrazolio o tratamento de 10 horas de embebição, três horas de imersão na solução com concentração de 0,075\% de sal de Tetrazólio (Tabela 8). Tal escolha deu-se por meio dos resultados apresentados nas Tabelas $3-6$, conforme a metodologia estabelecida. Como resultados, podemos descrever que o tratamento de substrato papel a $250 \mathrm{C}$ apresentou correlação positiva com o tratamento do experimento de Tetrazólio que foi conduzido com a proposição de 10 horas de embebição em água e três horas de imersão na solução com concentração de $0,075 \%$ (Tabela 1) das sementes trabalhadas. Podendo estes serem recomendados para a análise de viabilidade e vigor de sementes de Aspidosperma pyrifolium.

Tabela 8 - Análise da Correlação de Pearson realizada entre valores médios obtidos no ensaio de germinação em relação aos tratamentos em que foram utilizadas as combinações dos substratos Vermiculita e Rolo de Papel com as temperaturas constantes ou não de 25,30 e $25-30^{\circ} \mathrm{C}$ (em separado) com o resultado obtido no ensaio de tetrazólio para o tratamento de 10 horas de embebição, três horas de imersão na solução com concentração de $0,075 \%$ de sal de Tetrazólio, em sementes de Aspidosperma pyrifolium.

\begin{tabular}{cc}
\hline & $\begin{array}{c}\text { Tetrazólio - 10 horas de embebição, três horas de } \\
\text { imersão na solução com concentração de } 0,075 \%\end{array}$ \\
\hline Tetrazólio - 10 horas de embebição, três horas de & 1,00 \\
imersão na solução com concentração de $0,075 \%$ & 0,25 \\
Germinação - Vermiculita $25^{\circ} \mathrm{C}$ & 0,27 \\
Germinação - Vermiculita $30^{\circ} \mathrm{C}$ & 0,00 \\
Germinação - Vermiculita $25-30^{\circ} \mathrm{C}$ & 0,94 \\
Germinação - Rolo de papel $25^{\circ} \mathrm{C}$ & $-0,37$ \\
Germinação - Rolo de papel $30^{\circ} \mathrm{C}$ & $-0,74$ \\
Germinação - Rolo de papel $25-30^{\circ} \mathrm{C}$ & \\
\hline
\end{tabular}

Fonte: Autores.

Ademais, o resultado do teste de germinação de sementes de A. pyrifolium apontou média de $67 \%$ de sementes germinadas, no substrato rolo de papel, e temperatura alternada de 25-300 C. A comparação com os resultados obtidos no teste do tetrazólio, considerando apenas as classes I e II (sementes viáveis e vigorosas) e nas condições consideradas adequadas para condução do teste nesta pesquisa: 10h de Embebição, 3h de Imersão e Concentração da solução de 0,075\%, com valor de 63,4\%, mostra que o método é eficaz na avaliação da viabilidade de sementes da espécie em estudo, pois não há diferenças estatísticas significativas entre a porcentagem média entre ambos os testes, nas condições mencionadas. Desta forma, o valor obtido no teste de tetrazólio, nas melhores condições para execução deste, e para que se possa obter resultados mais rápidos, é razoável que se recomende o uso do teste de tetrazólio nas análises laboratoriais, se outras condições o permitirem.

A diferença de $5 \%$ entre a porcentagem de sementes viáveis e vigorosas do teste de tetrazólio e de sementes germinadas no teste de germinação foi considerada permitida para soja, uma espécie domesticada (França-Neto, 1998). Para espécies florestais não há determinação quanto a estas diferenças, que devem considerar que são espécies silvestres e que o teste de tetrazólio avalia o embrião das sementes e não plântulas, como no teste padrão de germinação (Cunha \& Gomes, 2015). 
Research, Society and Development, v. 10, n. 9, e57910918273, 2021

(CC BY 4.0) | ISSN 2525-3409 | DOI: http://dx.doi.org/10.33448/rsd-v10i9.18273

\section{Conclusão}

Os protocolos de Germinação (substrato papel a $25^{\circ} \mathrm{C}$ por oito dias) e Tetrazolio (10h de embebição e $3 \mathrm{~h}$ de imersão na solução com concentração de $0,075 \%$ ) podem testados em sementes de outras populações desta espécie para a verificação de sua efetividade.

\section{Referências}

Abbade, L. C., \& Takaki, M. (2014). Teste de tetrazólio para avaliação da qualidade de sementes de Tabebuia roseoalba (Ridl.) Sandwith-Bignoniaceae, submetidas ao armazenamento. Revista Árvore, 38, 233-240.

Andrade, A. C. S. D., Pereira, T. S., Fernandes, M. D. J., Cruz, A. P. M., \& Carvalho, A. S. D. R. (2006). Substrato, temperatura de germinação e desenvolvimento pós-seminal de sementes de Dalbergia nigra. Pesquisa Agropecuária Brasileira, 41, 517-523.

Brasil. Ministério da Agricultura, Pecuária e Abastecimento. Regras para análise de sementes. P. imprenta: Brasília, DF (Brazil). 2009. 395 p..

Barrozo, L. M., Alves, E. U., dos Santos Silva, R., dos Anjos Neto, A. P., dos Santos, M. D. M. S., \& da Silva, B. F. (2014). Substratos e temperaturas para testes de germinação e vigor de sementes de Inga laurina (Sw.) Willd. Bioscience Journal, 30.

Costa, C. J., \& Santos, C. P. D. (2010). Teste de tetrazólio em sementes de leucena. Revista Brasileira de sementes, $32,66-72$.

Fogaça, C. A., Malavasi, M. D. M., Zucareli, C., \& Malavasi, U. C. (2006). Aplicação do teste de tetrazólio em sementes de Gleditschia amorphoides Taub. Caesalpinaceae. Revista Brasileira de Sementes, 28, 101-107.

Freitas, V. L.O., Alves, T. H. S., Lopes, R. D. M. F., \& de Lemos Filho, J. P. (2012) Biometria de frutos e sementes e germinação de sementes de Dimorphandra mollis Benth. e Dimorphandra wilsonii Rizz.(Fabaceae-Caesalpinioideae) Fruit and seed biometry and germination of Dimorphandra mollis Benth. and Dimorphandra wilsonii Rizz.(Fabaceae-Caesalpinioideae) seed.

Grabe, D.F. (1976). Manual do Teste de Tetrazólio em Sementes. Brasília: AGIPLAN.. 85 p.

Guedes, R. S., Alves, E. U., Gonçalves, E. P., Bruno, R. D. L. A., Júnior, J. M. B., \& de Medeiros, M. S. (2009). Germinação de sementes de Cereus jamacaru DC. em diferentes substratos e temperaturas. Acta Scientiarum. Biological Sciences, 31(2), 159-164.

Guedes, R. S., Alves, E. U., Gonçalves, E. P., Viana, J. S., Silva, K. B., \& Gomes, M. S. S. (2010). Metodologia para teste de tetrazólio em sementes de Amburana cearensis (Allemão) AC Smith. Revista Brasileira de Plantas Medicinais, 12, 120-126.

Kopper, A. C., Malavasi, M. D. M., \& Malavasi, U. C. (2010). Influência da temperatura e do substrato na germinação de sementes de Cariniana estrellensis (Raddi) Kuntze. Revista Brasileira de Sementes, 32, 160-165.

Lazarotto, M., Piveta, G., Muniz, M. F. B., \& Reiniger, L. R. S. (2011). Adequação do teste de tetrazólio para avaliação da qualidade de sementes de Ceiba speciosa. Semina: Ciências Agrárias, 32(4), 1243-1250.

LIMA, D. D., \& Garcia, L. C. (1996). Avaliação de métodos para o teste de germinação em sementes de Acacia mangium Willd. Embrapa Amazônia Ocidental-Artigo em periódico indexado (ALICE).

Lorenzi, H. (2002) Árvores brasileiras: manual de identificação e cultivo de espécies arbóreas nativas do Brasil. V. 2, 3 ed. Instituto Plantarum. 384p.

Maciel, C. G., Bovolini, M. P., Finger, G., Pollet, C. S., \& Muniz, M. F. B. (2013). Avaliação de temperaturas e substratos na germinação de sementes de Jacaranda mimosifolia D. Don. Floresta e Ambiente, 20, 55-61.

Moore, R. P. (1972). Interpretation of color differences in tetrazolium testing. Seed Technologist News, 44(3), 22-24.

Medeiros, J. A. D. D., Nunes, S. P. L., Félix, F. C., Ferrari, C. D. S., Pacheco, M. V., \& Torres, S. B. (2020). Vigor test of (strong) normal intact Amburana cearensis (Allemão) AC Smith seedlings. Journal of Seed Science, 42.

Nogueira, F. C. B., Silva, J. W. L., Bezerra, A. M. E., \& Medeiros Filho, S. (2012). Efeito da temperatura e luz na germinação de sementes de Luetzelburgia auriculata (Alemão) Ducke-Fabaceae. Acta Botanica Brasilica, 26, 772-778.

PACHECO. V. M. et al. Efeito de Temperaturas e Substratos na Germinação de Sementes de Myracrodruon urundeuva fr. All. (Anacardiaceae). Revista Árvore, vol. 30, n 3, 2006. Pacheco, M. V., Matos, V. P., Ferreira, R. L. C., Feliciano, A. L. P., \& Pinto, K. M. S. (2006). Efeito de temperaturas e substratos na germinação de sementes de Myracrodruon urundeuva Fr. All.(Anacardiaceae). Revista Árvore, 30, 359-367.

Rego, S. S., Nogueira, A. C., Kuniyoshi, Y. S., \& Santos, Á. F. D. (2009). Germinação de sementes de Blepharocalyx salicifolius (HBK) Berg. em diferentes substratos e condições de temperaturas, luz e umidade. Revista Brasileira de Sementes, 31, 212-220.

Santos, R. C. D., Carneiro, A. D. C. O., Pimenta, A. S., Castro, R. V. O., Marinho, I. V., Trugilho, P. F., ... \& Castro, A. F. N. M. (2013). Potencial energético da madeira de espécies oriundas de plano de manejo florestal no estado do Rio Grande do Norte. Ciência Florestal, 23, 491-502.

Silva, L. M. D. M., \& Aguiar, I. B. D. (2004). Efeito dos substratos e temperaturas na germinação de sementes de Cnidosculus phyllacanthus Pax \& K. Hoffm.(faveleira). Revista Brasileira de sementes, 26, 9-14. 